\title{
A review of Pseudohypatopa Sinev (Lepidoptera: Coleophoridae: Blastobasinae: Holcocerini), with descriptions of two new species
}

\author{
Hui Zhen \& Houhun Li*
}

\begin{abstract}
Zhen, H. \& Li, H. 2008: A review of Pseudohypatopa Sinev (Lepidoptera: Coleophoridae: Blastobasinae: Holcocerini), with descriptions of two new species. - Entomol. Fennica 19: 241-247.

The genus Pseudohypatopa Sinev is reviewed, aided by collections from eight provinces of China. Of the four species reported, Pseudohypatopa longitubulata and $P$. paulilobata are described as new, and P. longicornutella Park is newly recorded from China. Photographs of the pinned adults and male and female genitalia, along with a key to the species are provided.

H. Zhen \& H. Li, Lepidopterology Lab, College of Life Sciences, Nankai University, Tianjin 300071, P. R. China; *corresponding author's e-mail: lihouhun @nankai.edu.cn
\end{abstract}

Received 10 August 2007, accepted 20 November 2007

\section{Introduction}

Sinev (1986) established Pseudohypatopa based upon the type species, Holcocera pulverea (Meyrick, 1907). Like most Blastobasinae, members of Pseudohypatopa are generally small to mediumsized, dull-patterned moths. The genus is defined by having the first flagellomere not notched, the gnathos weakly fused to tegumen, and the aedeagus narrowly bifurcate apically. To date the genus contains two species, which occur in the Oriental and Palaearctic regions. Pseudohypatopa pulverea (Meyrick) was described from India (Meyrick 1907), which was placed originally in the genus Blastobasis and transferred to Hypatima (Meyrick 1908), and then to Holcocera (Walsingham \& Durrant 1909), before Sinev (1986) provided its present assignment. Pseudohypatopa longicornutella Park was reported from South Korea (Park 1989). Sinev (1999) redescribed the genus and reported $P$. longicornu- tella from Russian Far East. This paper reports four species of Pseudohypatopa, including descriptions of two new species based on the specimens collected in China.

\section{Materials and methods}

This study is based on the examination of specimens collected using light traps in Fujian, Guangdong, Guangxi, Henan, Hubei, Shaanxi, Tianjin and Zhejiang, China. External characters of adults were examined using an Olympus SZX7 stereomicroscope, with a calibrate ocular micrometer. Slide-prepared genitalia were examined using specimens mounted in Canada balsam following Li and Zheng (1996). Terminology of genitalia follows Adamski and Brown (1989). All the studied specimens are deposited in the Insect Collection, College of Life Sciences, Nankai University, Tianjin, China. 


\section{Taxonomy}

\subsection{Genus Pseudohypatopa Sinev, 1986}

Pseudohypatopa Sinev, 1986: 67.

Type species. Holcocera pulverea (Meyrick, 1907), by original designation.

Diagnostic characters. Antenna with flagellomeres ciliated beneath, and having more and longer cilia in male; scape with pecten; first flagellomere not notched. Forewing with $\mathrm{R}-\mathrm{Cu}$ cell very long, $R_{4}$ and $R_{5}$ stalked in basal half, $M_{2}$ $\mathrm{CuA}_{2}$ closely situated at base and very short; hindwing with $\mathrm{M}_{3}$ and $\mathrm{CuA}$ fused only in basal half and having a common stalk with $\mathrm{M}_{2}$. Gnathos weakly fused to tegumen; valva with upper division having narrow proximal flange; aedeagus narrowly bifurcate apically and forming two lobes; ductus bursae finely spined in posterior part, and corpus bursae with a large plate-like signum.

Biology. Hosts are known for two species. Pseudohypatopa pulverea (Meyrick) is a predator of the scale insect, Kerria lacca (Kerr) (Kerriidae), in China, India and northern Thailand, and P. longicornutella (Park) feeds in cones of Pinus densiflora Sieb. and Zucc. (Pinaceae) (Park 1989).

Distribution. Pseudohypatopa is distributed in China, Korea, India, Vietnam, Russia (Far East) and Transcaucasia.

Remarks. The genus Pseudohypatopa resembles Holcoceroides, but it differs from the latter by $\mathrm{CuA}_{1}$ in forewing present, $\mathrm{M}_{3}$ and $\mathrm{CuA}_{1}$ in hindwing not fused in distal half; valva having a narrow proximal flange, vinculum narrow, aedeagus narrowly bifurcated, and signum present. In Holcoceroides, $\mathrm{CuA}_{1}$ is absent in forewing, $\mathrm{M}_{3}$ and $\mathrm{CuA}_{1}$ in hindwing are fused completely; the valva has a large proximal flange, the vinculum is broad, the aedeagus is broadly bifurcated, and the signum is absent.

We follow Adamski and Brown (1989), who suggested that Pseudohypatopa Sinev should belong to the Holcocerinae. Members of this genus share the following characters: male genitalia with a ring-like sclerite at the base of aedeagus; female eighth sternum setose anteriorly, with an emarginated anterior margin; ductus seminalis arising distantly from ostium brusae. These char- acters are apomorphies supporting the monophyly of Holcocerinae. The subfamily was degraded to Holcocerini in Adamski and Hodges (1996).

\subsection{Key to species of Pseudohypatopa based on genitalia}

1. Male

- Female

2. Distal lobes of aedeagus expanded, with apex smoothly rounded or with large dentitions (Fig. 1a, c)

- Distal lobes of aedeagus slender, with apex bluntly or sharply pointed (Fig. 1b, d) 4

3. Juxta subtrapezoidal, distal lobes of aedeagus dentate at apex (Fig. 1a)

P.pulverea (Meyrick)

- Juxta triangular, distal lobes of aedeagus smoothly rounded at apex (Fig. 1c)

P. longitubulata Zhen \& Li

4. Gnathos with dorsal margin slightly sinuate, distal lobes of aedeagus sharply pointed at apex (Fig. 1b) P. longicornutella Park

- Gnathos with dorsal margin notched medially, distal lobes of aedeagus bluntly pointed at apex (Fig. 1d) P.paulilobata Zhen \& Li

5. Signum small, $1 / 6-1 / 3$ diameter of corpus bursae (Fig. 2a, b)

6

- Signum large, nearly $1 / 2$ diameter of corpus bursae (Fig. 2c) P. longitubulata Zhen \& Li

6. Signum about 1/6 diameter of corpus bursae, ductus bursae with no more than two coils (Fig. 2b)

P. longicornutella Park

- Signum about $1 / 3$ diameter of corpus bursae; ductus bursae with several coils (Fig. 2a)

P.pulverea (Meyrick)

\subsection{Species descriptions}

3.3.1. Pseudohypatopa pulverea (Meyrick, 1907) (Figs. 1a, 2a, 3a)

Blastobasis pulverea Meyrick, 1907: 151.

Hypatima pulverea (Merick, 1907): Meyrick, 1908: 638.

Holcocera pulverea (Merick, 1907): Walsingham \& Durrant, 1909: 47. 


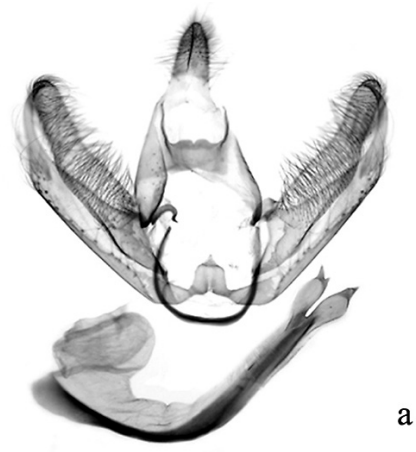

a

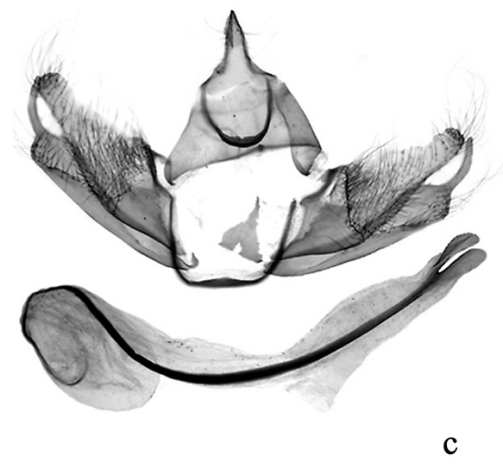

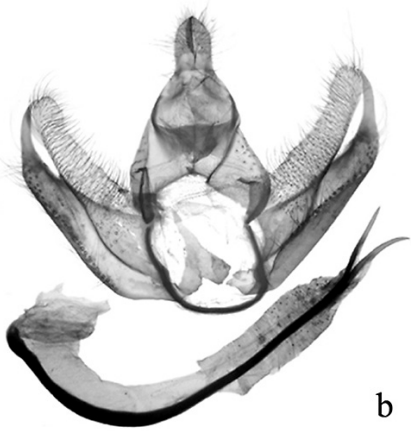

b

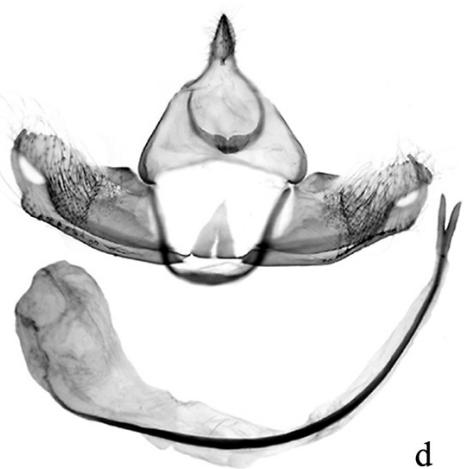

Fig. 1. Male genitalia of Pseudohypatopa spp. - a. P. pulverea (Meyrick) (slide No.

ZH07051). - b. P. longicornutella Park (slide No. ZH07068). - c. P. longitubulata sp. n., paratype (slide No.

ZH07050). - d. P. paulilobata sp. n., holotype (slide No. ZH07033).
Pseudohypatopa pulverea (Meyrick, 1907): Sinev, 1986: 67.

Material examined. China: 1 o, Nanping, Shangsi (2209’N, 10758'E), Guangxi Province, $770 \mathrm{~m}$ a.s.1., 3.IV.2002, leg. Shulian Hao and Huaijun Xue.

Redescription. Adult (Fig. 3a): Head: darkbrown mottled white. Labial palpus with whitetipped dark-brown scales. Antenna with scape mostly dark-brown intermixed with pale yellow on dorsal surface, grayish yellow on ventral surface; flagellum brown on dorsal surface, grayish yellow on ventral surface. Thorax: mesonotum and tegulae dark-brown intermixed with white mesially. Legs: outer surface dark-brown mottled white except femur of hindleg silvery white, tarsomeres white apically; inner surface yellowish white. Forewing length: $6.0 \mathrm{~mm}$; dorsal surface dark-brown intermixed with white, darkbrown spots at middle and end of cell as well as at middle of fold; ventral surface brown; fringe scales grayish brown. Hindwing: dorsal surface grayish yellow; ventral surface and fringe scales gray.

Male genitalia (Fig. 1a): Uncus broad, ven- trally keeled. Gnathos with dorsal margin arched and notched mesially, ventral margin almost straight. Valva with upper division broad in basal $3 / 5$, slightly narrow in distal $2 / 5$, bluntly rounded at apex, distal $4 / 5$ setose; proximal flange almost straight; lower division narrowed from base to sharp and inwardly curved apex. Vinculum narrow. Juxta subtrapezoidal. Aedeagus about 1.7 times length of valva, distal lobes about its $1 / 6$ length, expanded, dentate apically.

Female genitalia (Fig. 2a): Anterior apophyses about 2/5 length of posterior apophyses. Ductus bursae coiled, about eight times length of anterior apophyses. Corpus bursae small, ovate, its maximum width about 1.3 times that of eighth tergum; signum small, rounded, nearly $1 / 3$ diameter of corpus bursae.

Biology. Pseudohypatopa pulverea (Meyrick) is a predator of the lac insect Kerria lacca (Kerr). According to Sinev (1986), the species has two generations in Transcaucasia, four to six generations in China and India. Larvae feed eggs, larvae and female adults of Kerria lacca.

Distribution. China (Guangxi, Yunnan), Vietnam, India, Russia (Far East) and Transcaucasia. 

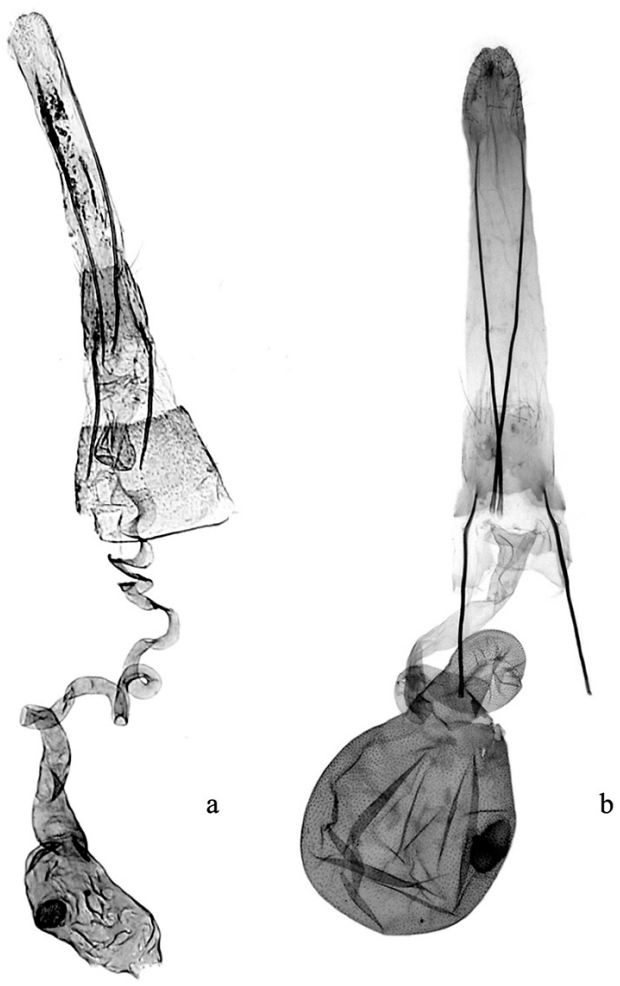

Remarks. This species can be distinguished from other species of the genus by the dorsal margin of gnathos arched, the juxta subtrapezoidal, the distal lobes of aedeagus expanded and dentate apically; the corpus bursae narrow, its maximum width about 1.3 times that of eighth tergum, the signum rounded, about $1 / 3$ diameter of corpus bursae.

\subsubsection{Pseudohypatopa longicornutella Park, 1989 (Figs. 1b, 2b, 3b)}

Pseudohypatopa longicornutella Park, 1989: 76; Sinev, 1999: 97.

Material examined. China: 2 ふ, 2 ๆ, Mt. Jiulong, Jixian $\left(40^{\circ} 03^{\prime} \mathrm{N}, 117^{\circ} 02^{\prime} \mathrm{E}\right)$, Tianjin, 200 $\mathrm{m}$ a.s.1., 27-28.VI.2004, 1 ô, $130 \mathrm{~m}$ a.s.1., 9.VI.

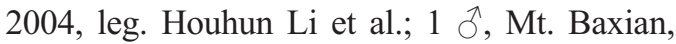
Jixian $\left(40^{\circ} 03^{\prime} \mathrm{N}, 117^{\circ} 02^{\prime} \mathrm{E}\right)$, Tianjin, $450 \mathrm{~m}$ a.s.1.,

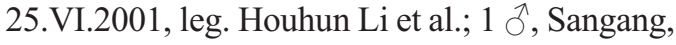
Mt. Wuyi $\left(27^{\circ} 43^{\prime} \mathrm{N}, 118^{\circ} 01^{\prime} \mathrm{E}\right)$, Fujian Province, $740 \mathrm{~m}$ a.s.1., 17.V.2004, leg. Haili Yu; 5 ô, 3 ㅇ, Lingshan Temple, Luoshan $\left(32^{\circ} 12^{\prime} \mathrm{N}\right.$, $\left.114^{\circ} 32^{\prime} \mathrm{E}\right)$, Henan Province, $350 \mathrm{~m}$ a.s.1., 2123.V.2000, leg. Haili Yu; Lichuan $\left(30^{\circ} 11^{\prime} \mathrm{N}\right.$,

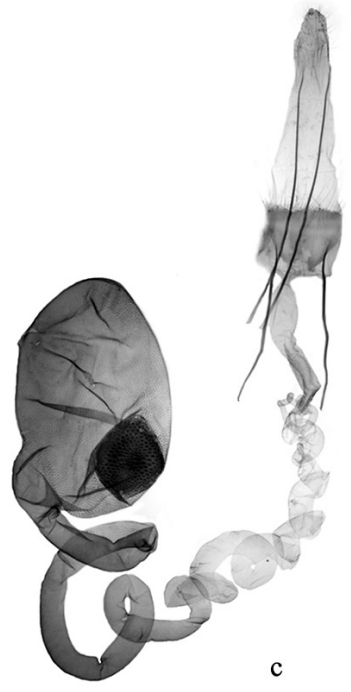

Fig. 2. Female genitalia of Pseudohypatopa spp. - a. P. pulverea (Meyrick). - b. P. longicornutella Park (slide No. ZH07113). - c. P. longitubulata sp. n., paratype (slide No. ZH07112).

108 34'E), Hubei Province: 1 đ̊, 700 m a.s.1., 30.VII.1999, 1 ㅇ, 1,100 m a.s.1., 2.VIII.1999, leg. Houhun Li et al.; 2 ô, 4 ๆ, Mt. Baling, Jingzhou $\left(30^{\circ} 19^{\prime} \mathrm{N}, 112^{\circ} 11^{\prime} \mathrm{E}\right)$, Hubei Province, $100 \mathrm{~m}$ a.s.1., 26.VII.2003, leg. Shulian Hao; 1 o, Tieyupu, Danfeng (3342'N, 110 21'E), Shaanxi Province, $680 \mathrm{~m}$ a.s.1., 29.V.1994, leg. Jin Zhou.

Description. Adult (Fig. 3b): Head: darkbrown mottled white. Labial palpus dark-brown intermixed with somewhat white. Antenna with scape grayish brown to dark-brown intermixed with grayish white on dorsal surface, pale yellow on ventral surface; flagellum brown on dorsal surface, pale yellow on ventral surface. Thorax: mesonotum and tegulae dark-brown. Legs: outer surface dark-brown mottled white, tarsomeres white apically; inner surface yellowish white. Forewing length: 5.0-6.0 mm. Abdomen: yellowish white except distal margins of terga 2-7 (males) and 2-6 (females) with several transverse rows of ocherous yellow spiniform abdominal setae.

Male genitalia (Fig. 1b): Uncus broad, with a rounded apex, ventrally keeled. Gnathos with dorsal margin slightly sinuate, ventral surface 

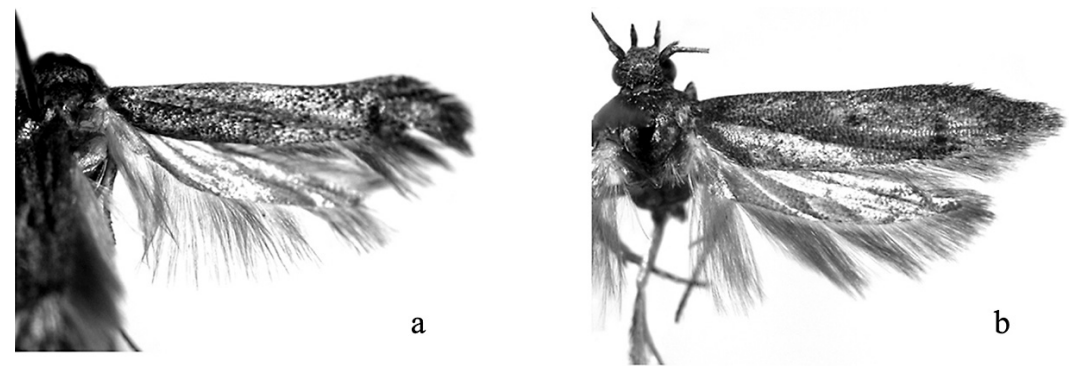

Fig. 3. Adults of Pseudohypatopa spp. - a. $P$. pulverea (Meyrick), ô. - b. P. longicornutella Park, ô. - c. P. longitubulata sp. n., holotype స. - d. P. paulilobata sp. n., holotype $\hat{\jmath}$.
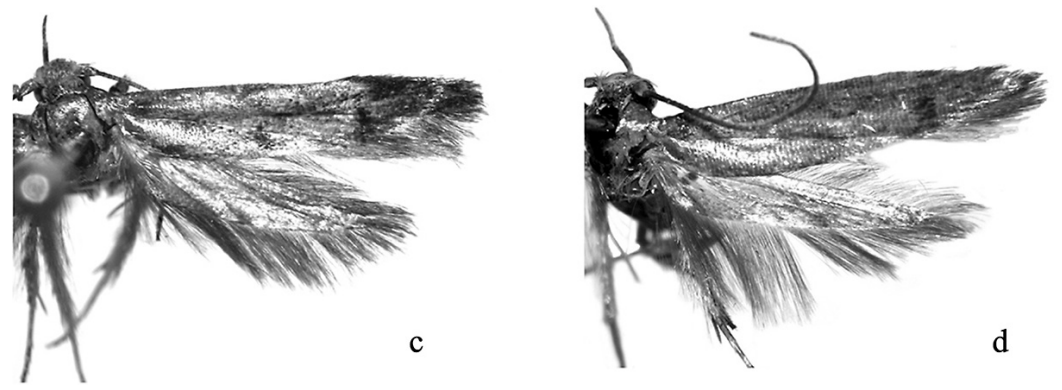

slightly arched. Upper division of valva narrowed gradually to $3 / 4$, distal $1 / 4$ with dorsal and ventral margins nearly parallel, distal $4 / 5$ setose, apex broadly rounded; proximal flange slightly arched at $2 / 5$; lower division of valva narrowed from base, and curved inward forming a pointed apex. Vinculum narrow. Juxta triangular. Aedeagus about twice length of valva, with distal lobes about its $1 / 6$ length, slender and sharp apically.

Female genitalia (Fig. 2b): Anterior apophyses about $1 / 2$ length of posterior apophyses. Ostium bursae broad. Ductus bursae with no more than two coils, about 2.5 times length of anterior apophyses. Corpus bursae large and rounded, its maximum width about twice that of eighth tergum; signum spinulate, oval, nearly $1 / 6$ diameter of corpus bursae.

Host plant. Pinus densiflora Sieb. and Zucc. (Park 1989).

Distribution. China (Tianjin, Fujian, Henan, Hubei, Shaanxi), Korea, Russia (Far East).

Remarks. Pseudohypatopa longicornutella is newly reported from China. It is similar to $P$. pulverea by having a broad uncus, and the lower division of valva narrowed gradually from base to an inwardly curved spine-like process. But it differs from $P$. pulverea by having the dorsal margin of gnathos slightly sinuate, the juxta triangular, the aedeagus with distal lobes slender and sharp apically; the ductus bursae with no more than two coils, and the signum oval, about 1/6 diameter of corpus bursae.

\subsubsection{Pseudohypatopa longitubulata $\mathrm{sp} . \mathrm{n}$.}

(Figs. 1c, 2c, 3c)

Type material. Holotype ${ }^{\lambda}$, China: Mt. Dadong, Lianzhou ( $\left.24^{\circ} 29^{\prime} \mathrm{N}, 112^{\circ} 14^{\prime} \mathrm{E}\right)$, Guangdong Province, $650 \mathrm{~m}$ a.s.1., 22.VI.2004, leg. Dandan Zhang, genitalia slide No. ZH07077. Paratypes: 1 $\hat{\jmath}, 1$ o , data same as holotype; $2 \hat{\jmath}$, Nanping, Shangsi $\left(22^{\circ} 05^{\prime} \mathrm{N}, 107^{\circ} 35^{\prime} \mathrm{E}\right)$, Guangxi Province, $770 \mathrm{~m}$ a.s.1., 3.IV.2002, leg. Shulian Hao and Huaijun Xue.

Diagnosis. Pseudohypatopa longitubulata is similar to P. pulverea (Meyrick) by sharing the gnathos narrow, the distal lobes of aedeagus expanded; the ductus bursae coiled. But it differs from the latter by having the gnathos with dorsal margin almost straight, lower division of valva with basal $3 / 4$ broad, distal 1/4 abruptly narrowed and blunt apically, the aedeagus about 2.5 times length of valva and its distal lobes dentate marginally; the signum nearly $1 / 2$ diameter of the corpus bursae.

Description. Adult (Fig. 3c): Head: darkbrown intermixed with grayish yellow. Labial palpus with dark-brown scales white apically. Antenna with scape grayish yellow mottled darkbrown on dorsal surface, yellowish white on ven- 
tral surface; flagellum grayish brown on dorsal surface, grayish white on ventral surface. Thorax: mesonotum and tegula grayish brown. Legs: outer surface dark-brown mottled white except femur of hindleg yellowish white, tarsomeres pale yellow apically; inner surface pale yellow. Forewing length: $6.0-7.0 \mathrm{~mm}$ [including fringe scales]; dorsal surface grayish brown, intermixed with dark-brown scales, with a faint dark-brown fascia extending from costal $2 / 5$ to middle of dorsum, and dark-brown spot situated at distal 2/5 and end of cell, costa dark brown in distal 1/3; ventral surface uniformly brown; fringe scales dark-brown tipped with white. Hindwing: dorsal surface pale brown, ventral surface brown, fringe scales pale brown.

Male genitalia (Fig. 1c): Uncus narrow, ventrally keeled. Gnathos narrow, with dorsal margin straight and having a small notch mesially, ventral margin slightly arched. Upper division of valva gradually narrowed to about $3 / 4$, distal $1 / 4$ with dorsal and ventral margins nearly parallel, apex bluntly rounded, distal $3 / 4$ setose; proximal flange slightly arched mesially; lower division of valva with basal $3 / 4$ broad, distal $1 / 4$ abruptly narrowed and blunt apically, its width about $1 / 3$ of that at basal 3/4, gently curved inward. Vinculum narrow, slightly protrudent dorsally. Juxta triangular. Aedeagus about 2.5 times length of valva; distal lobes about its 1/9 length, rounded apically, dentate marginally.

Female genitalia (Fig. 2c): Posterior apophyses about three times length of anterior apophyses. Ostium bursae broad infundibulate. Ductus bursae coiled, about eight times length of anterior apophyses. Corpus bursae large, ovate; signum rhombic, spinulate, about $1 / 2$ diameter of corpus bursae.

Distribution. China (Guangdong, Guangxi).

Etymology. The specific name is derived from the Latin prefix long-meaning long, and the Latin tubulatus meaning tubular, referring to the long ductus bursae.

\subsubsection{Pseudohypatopa paulilobata sp. $\mathrm{n}$.}

(Figs. 1d, 3d)

Type material. Holotype $\widehat{\jmath}$, China: Wuyanling, Taishun (2734'N, 119²2'E), Zhejiang Provin- ce, $680 \mathrm{~m}$ a.s.1., 29.VII.2005, leg. Yunli Xiao, genitalia slide No. ZH07033.

Diagnosis. Pseudohypatopa paulilobata is similar to $P$. longicornutella by sharing the gnathos narrow, the juxta triangular, the distal lobes of aedeagus slender. But it differs from the latter by the gnathos with a medial notch on dorsal margin, valva with proximal flange broader than the latter, lower division of valva with basal $3 / 4$ broad, distal $1 / 4$ abruptly narrowed and slightly blunt apically, the distal lobes of aedeagus about $1 / 9$ of its entire length, bluntly pointed at apex.

Description. Adult (Fig. 3d): Head: grayish yellow. Labial palpus yellowish brown intermixed with dark-brown. Antenna with scape white mottled grayish brown on dorsal surface, ocherous on ventral surface; flagellum darkbrown on dorsal surface, grayish brown on ventral surface. Thorax: mesonotum and tegula grayish brown. Legs: outer surface grayish brown intermixed with white except femora of mid- and hindlegs yellowish white, tarsomeres white apically; inner surface with femora yellowish white, tibiae and tarsi pale ochreous. Forewing length: $5.5 \mathrm{~mm}$ (including fringe scales); dorsal surface gray, dark-brown spots at middle and end of cell, the later larger; ventral surface uniformly brown; fringe scales grayish brown. Hindwing: dorsal surface gray; ventral surface grayish brown; fringe scales grayish brown.

Male genitalia (Fig. 1d): Uncus narrow, ventrally keeled. Gnathos narrow, with dorsal margin straight and having a small notch mesially, ventral margin heavily sclerotized mesially. Upper division of valva with basal $2 / 3$ broad, distal $1 / 3$ slightly narrowed to bluntly rounded apex; proximal flange arched at distal $1 / 4$; lower division of valva with basal $3 / 4$ broad, distal $1 / 4$ abruptly narrowed, its width approximately $1 / 2$ of that at basal 3/4, curved inward, slightly blunt apically. Vinculum narrow, slightly protrudent ventrally. Juxta triangular. Aedeagus about three times length of valva, distal lobes slender, about its $1 / 9$ length, blunt apically.

Female: Unknown.

Distribution. China (Zhejiang).

Etymology. The specific name is derived from the Latin prefix paul- meaning small, and the Latin lobatus meaning lobar, referring to the short distal lobes of aedeagus. 
Acknowledgments. We are grateful to Dr. D. Adamski, Department of Entomology, National Museum of Natural History, Smithsonian Institution, Washington, for his critical comments and providing the female image of Pseudohypatopa pulverea (Meyrick). We also thank to Dr. S. Yu. Sinev, the Zoological Institute, St. Petersburg, for sending us helpful papers and Dr. O. Bidzilya, Kiev National Taras Shevchenko University, Kiev, for helping us to translate the Russian paper. This study was supported by the National Natural Science Foundation of China (No. 30470211).

\section{References}

Adamski, D. \& Brown, R. L. 1989: Morphology and Systematics of North American Blastobasidae (Lepidoptera: Gelechioidea). - Mississippi Agricultural and Forestry Experiment Station Technical Bulletin 165, Mississippi Entomological Museum No. 1. 70 pp.

Adamski, D. \& Hodges, R. W. 1996: An annotated list of North American Blastobasinae (Lepidoptera: Gelechioidea: Coleophoridae). - Proceedings of the Entomological Society of Washington 98: 708-740.
Li, H. H. \& Zheng, Z. M. 1996: Methods and techniques of specimens of Microlepidoptera. - Journal of Shaanxi Normal University (Natural Science Edition) 24: 6370. [In Chinese].

Meyrick, E. 1907: Descriptions of Indian Microlepidoptera V. - Journal of Bombay Natural History Society 18: $137-160$.

Meyrick, E. 1908: Descriptions of Indian Microlepidoptera VII. - Journal of Bombay Natural History Society 18: 613-638.

Park, K. T. 1989: A review of Blastobasidae (Lepidoptera) in Korea. - Korean Journal of Applied Entomology 28: 76-81.

Sinev, S. Yu. 1986: A review of blastobasid moths (Lepidoptera, Blastobasidae) in the fauna of the USSR. Trudy Zoologicheskogo Instituta 145: 53-71. [In Russian].

Sinev, S. Yu. 1999: Blastobasidae. — In: Ler, P. A. (ed.), Key to the insects of Russian Far East. Vol. V. Trichoptera and Lepidoptera. Pt 2: 92-101. Dal'nauka,Vladivostok. 669 pp. [In Russian].

Walsingham, L. \& Durrant, J. H. 1909: Revision of the nomenclature of Microlepidoptera. — Entomologist's Monthly Magazine 45: 46-52. 